\title{
Evaluation of Anti-Diabetic and Anti-lipidemic Activities of Aqueous Leaf Extract of Millettia aboensis and Its Effect on Pancreatic Histology of Alloxan-Induced Diabetic Rats
}

\author{
Onyegeme-Okerenta Blessing Minaopunye*, Essien Eka Bassey \\ Department of Biochemistry, Faculty of Biological \& Chemical Sciences, College of Natural \& Applied Sciences, University of Port \\ Harcourt, Rivers State, Nigeria
}

Email address:

blessing.onyegeme-okerenta@uniport.edu.ng (Onyegeme-Okerenta B. M.), mmedara2002@yahoo.com (E. E. Bassey)

To cite this article:

Onyegeme-Okerenta Blessing Minaopunye, Essien Eka Bassey. Evaluation of Anti-Diabetic and Anti-lipidemic Activities of Aqueous Leaf Extract of Millettia aboensis and Its Effect on Pancreatic Histology of Alloxan-Induced Diabetic Rats. Advances in Biochemistry.

Vol. 3, No. 2, 2015, pp. 24-29. doi: 10.11648/j.ab.20150302.11

\begin{abstract}
Plants provide a potential source of anti-diabetic drugs and are widely used in several traditional systems of medicine to prevent diabetes. This study evaluated the anti-diabetic and anti-lipidemic activities of oral administration of aqueous leaf extract of Milletia aboensis in, and its effect on pancreatic histology of, alloxan-induced diabetic rats. Eighty rats were grouped into eight based on average body weights. Diabetes similar to that of type 1 in human was induced by a single intra-peritoneal injection of alloxan monohydrate a -diabetogenic agent ( $\left.160 \mathrm{mg} \mathrm{kg}^{-1}\right)$. After 120 hours of alloxan injection, the rats from Groups $2-8$ were confirmed diabetic having baseline fasting blood sugar levels $>8.5 \mathrm{mmol} / \mathrm{L}$. Group 1 served as normal control. The extract was administered twice daily for 21 days at doses of $500 \mathrm{mg} \mathrm{kg}^{-1}-2500 \mathrm{mg} \mathrm{kg}^{-1}$ in $\mathrm{Groups}^{4}-8$. Group 2 was treated with a standard diabetic drug, 'Metformin', while Group 3 (untreated and negative control) was diabetic with increased Total cholesterol (CHOL), low density lipoproteins (LDL), triacylglycerol (TAG) levels and reduced high density lipoproteins (HDL) level throughout the experiment. Glucose was assayed for on the $7^{\text {th }}, 14^{\text {th }}$ and $21^{\text {st }}$ day while $\mathrm{CHOL}$, HDL, LDL, and triglyceride were assayed on the $21^{\text {st }}$ day. A significant reduction $(p<0.05)$ in the fasting blood glucose levels of rats in Groups 4-8 was observed when compared to the normal control. Similarly, there was a significant decrease $(p<0.05)$ in TAG and LDL and a significant increase $(p<0.05)$ in HDL levels in groups treated with the extract when compared to Group 1 (normal control). A photomicrograph of the pancreatic cells was taken before and after treatment with aqueous leaf extract. The photomicrograph before treatment showed atrophic pancreatic islet with vacuolations which indicates significant damaged Islets of langerhans in the beta cells. After treatment the photomicrograph indicates significant cell regeneration and repair. The present investigation suggests that leaf extract of M. aboensis exhibits anti-diabetic and anti-lipidemic activities and positively affected pancreatic functions in alloxan-induced diabetes rats.
\end{abstract}

Keywords: Anti-Diabetic, Anti-lipidemic, Milletia aboensis, Alloxan, Pancreas, Photomicrographs

\section{Introduction}

Diabetes mellitus is a multiple aetiologic metabolic disorder characterized by chronic hyperglycemia with disturbances in carbohydrate and protein metabolism. It also involves chronic alterations in fat metabolism amongst others, basically resulting from the secretion of dysfunctional and/or insufficient endogenous insulin by the $\beta$-cells of the pancreas. The dramatic rise in the prevalence of obesity and diabetes has become a major global public health issue [1]. The problem is complex and requires strategies at different levels to prevent, control and manage [2]. The most recent global predictions by the International Diabetes Federation (IDF) suggest that there are currently 285 million people with diabetes worldwide. This is estimated to escalate to 438 million by 2030 , with a further half billion at high risk. Diabetes is looming as one of the greatest public health threats of the 21 st century [1].

The effects of diabetes mellitus include long-term damage, dysfunction and failure of various organs [3, 4]. In Nigeria, the World Health Organization (WHO) has disclosed that more than 1.71 million citizens above 15 years are diabetic, 
70,000 children under 15 years develop insulin dependent diabetes each year and if nothing is done, the number of diabetes sufferers will continue to escalate $[3,5]$.

The number of people that are suffering from this scourge is on the increase and the orthodox anti-diabetic agents are also relatively expensive and/or unavailable. The orthodox approach of managing diabetes is also faced with a lot of difficulties partly because several of the drugs used in managing diabetes pose a significant risk of inflicting heart disease, cancer [6] and no pill or injection to-date is able to address the problem of dying pancreatic beta cells, a fundamental dysfunction in diabetes [7]. Other factors include high cost of hospital management of the disease, non-availability of competent health personnel and the long distance patient has to walk to health facilities [8]. These reasons have favored the use of alternative medicine to stabilize the blood glucose level in most diabetic patients in some developing countries of the world. This has accelerated the global efforts to harness and harvest those medicinal plants that yield substantial amounts of potential phytochemicals showing beneficial effects in combating diabetes and diabetes-related complications.

All forms of diabetes have very serious effects on health. In addition to the consequences of abnormal metabolism of glucose, there are a number of long-term complications associated with the disease. Coronary artery disease, caused by lipid abnormalities, is commonly associated particularly in those with type 2 diabetes, and is the most common cause of death $[9,10,11]$. These lipid abnormalities include hypertriglyceridemia and reduced high-density lipoprotein (HDL) levels. While lipid abnormalities typically improve with better glycemic control, normalization does not usually occur. Although improved glycemic control may decrease the risk of developing these complications, diabetes remains a very significant cause of social, psychological and financial burdens in populations worldwide.

Alloxan, a diabetogenic agent, has been used to induce experimental diabetes due to the selective destruction of the insulin-producing pancreatic beta-islets. Alloxan induces a multiphasic blood glucose response when injected into to an experimental animal, which is accompanied by corresponding inverse changes in the plasma insulin concentration followed by sequential ultra-structural beta cell changes ultimately leading to necrotic cell death. It is a toxic glucose analogue, that produces free radicals and it is used in experiment with animals to induce diabetes (Alloxan diabetes), with characteristics similar to type 1 diabetes in humans $[12,13,14]$. The first phase that comes into view within the first minutes after alloxan injection is transient hypoglycemic phase that lasts maximally for 30 minutes [14]. This pancreatic $\beta$-cells destruction invariably causes absolute insulin deficiency that leads to hyperglycemia in the diabetic rats $[13,15]$. Alloxan induces irreversible diabetes mellitus after 24 hours following its administration and the condition proves to be chronic by laboratory tests after seven days.

Millettia aboensis is a medicinal plant (with little documented literature), used extensively by traditional medical practitioners in Southern Nigeria as a laxative, antimalarial and anti-inflammatory herb. It can alter the activities of the haemopoietic system [16] and has antimicrobial properties [17]. Millettia is a genus of legume in the Fabaceae (Pea) family. It consists of about 150 species, and has its geographical location in Asia, Western and Central African continent [18]. It occurs mostly in the forest zones of Nigeria, Cameroun and Equatorial Guinea. The present study aims to evaluate the anti-diabetic and anti-lipidemic activities of oral administration of aqueous leaf extract of $\mathrm{M}$. aboensis in, and its effect on pancreatic histology of, alloxan-induced diabetic rats.

\section{Materials and Methods}

\subsection{Plant Material and Preparation of Extract}

Fresh leaves of M. aboensis were collected from the medicinal garden of the Department of Pharmacy; University of Port Harcourt Rivers State, Nigeria. Identification and authentication of plant have been previously reported [16]. The leaves were subsequently cleaned, air-dried under room temperature of $27 \pm 1^{\mathrm{O}} \mathrm{C}$ for 14 days and pulverized using a grinder. The stock solution of the plant extract was prepared by weighing $200 \mathrm{~g}$ of the pulverized leave cold macerated in $500 \mathrm{ml}$ distilled water solution overnight. The resulting solution was filtered into a clean screw-cap bottle and store in the refrigerator throughout the experiment. Metformin, an anti-diabetic drug, used as reference drug in this study was bought from a Pharmacy shop by University of Port Harcourt Teaching Hospital, East-West Road, Port Harcourt.

\subsection{Preparation of Chemicals}

All laboratory reagents were freshly prepared and fresh distilled water was used when required.

For normal saline, $0.9 \mathrm{~g}$ of Sodium chloride $(\mathrm{NaCl})$ was dissolved in $10 \mathrm{ml}$ of distilled water; the solution was made up to $100 \mathrm{~mL}$ and stored in clean, dry, screw-cap bottle. One thousand, five hundred milligram of alloxan was weighed and dissolved in $10 \mathrm{~mL}$ of normal saline, stirred and the solution made-up to $100 \mathrm{ml}$. The required volume of alloxan to induce diabetes was calculated with respect to the average body weight of each group of the animals.

\subsection{Experimental Design}

Eighty (80) albino rats of Wistar strain weighing 140-230g of either sex, obtained from the Font Scientific Laboratory Animal Farm, No. 200 Uniport Road, Choba, were used. The rats were allowed to acclimatize in the experimental animal house unit for 7 days, during which they were fed with standard rodent diet and water was provided liberally, ad libitum. They were grouped into eight (8) of 10 rats each based on average body weights. This study was carried out following approval from the Departmental Ethical Committee on the Care and Use of Experimental Animals for Research. 


\subsection{Induction of Diabetes}

The animals were allowed to fast overnight but had free access to water and few hours prior to administration of alloxan; a fasting blood glucose test was conducted to obtain a baseline result. All the animal groups except the normal control group were induced by intra-peritoneal administration of $160 \mathrm{mg} \mathrm{kg} \mathrm{kg}^{-1}$ bodyweight alloxan monohydrate in normal saline [18]. The diabetic states of the rats were confirmed $120 \mathrm{hrs}$ after administering the alloxan.

\subsection{Administration of Leave Extract and Treatment of the Animals}

The experimental animals were grouped as follows:

- Group 1: Normal control - These non-diabetic rats were fed with conventional rat feed throughout the course of the experiment;

- Group 2: Positive control -diabetic rats were treated with $500 \mathrm{mg} \mathrm{kg}^{-1}$ bodyweight Metformin - a standard anti-diabetic drug.

- Group 3: Negative control - diabetic rats were not treated;

- Groups 4-8 diabetic rats were treated with leave extract of concentrations 500,1000, 1500, 2000 and $2500 \mathrm{mg}$ $\mathrm{kg}^{-1}$ bodyweight respectively.

Administration of Metformin into Group 2 and various concentrations of the extract to Groups 4-8 were by oral intubation twice daily for 21 days. Prior to this, each rat group was also adapted to the commercial feed and water ad libitum for the 21-day study period. Rats in Groups 1 and 3 (normal and negative control respectively) were given commercial feed and water ad libitum without the leaf extract or reference drug. The fasting glucose level for the rats in each group was monitored at 7-day interval.

\subsection{Blood and Pancreas Collection and Biochemical Analyses}

Blood collection for glucose estimation was by vein puncture technique. A sterile lancet was used to puncture the tail vein of the rats. Blood glucose was assayed by the glucose oxidase method, using a glucometer while total CHOL, HDL, LDL, and TAG were analyzed by kinetic methods kits from Randox, (United Kingdom) using a double-beam spectrophotometer. Only those rats with established fasting blood glucose $>8.5 \mathrm{mmol} / 1$ were included for subsequent treatment. The animals to be sacrificed were first anaesthetized with chloroform (inhalational anesthesia) followed by cervical dislocation. Each animal was placed on a dissecting slab and then cut along the thorax down the abdominal region; freshly dissected pancreas from each animal was fixed in buffered neutral formalin $(10 \%)$. The tissues were subjected to standard routine histological procedures [20]. The slides were viewed using the light microscope and observations were recorded at X40 magnification identifying both normal and degenerated pancreatic islet.

\subsection{Statistical Analysis}

Results were expressed as means \pm standard deviation $(\mathrm{M} \pm \mathrm{SD})$. Statistical analysis was performed using SPSS version 16.0 (Chicago, U.S.A). Data were analyzed using one-way analysis of variance (ANOVA) and significant difference was determined using post-Hoc Turkey's test for multiple comparisons at $(\mathrm{p}<0.05)$.

\section{Results}

Results obtained show that the aqueous leaf extract of $\mathrm{M}$. aboensis possesses anti-diabetic properties on alloxaninduced diabetic experimental rats. Administration of alloxan resulted in elevation of fasting blood glucose levels of rats in Groups 2 - 8, when compared to Group 1 (Fig.1). Twentyone days of daily treatment with the extract led to a dosedependent decrease in blood glucose levels. It was observed that by the $14^{\text {th }}$ day of treatment with the extract, fasting blood glucose level of Groups 4, 5 and 6 were significantly reduced $(\mathrm{p}<0.05)$. However by the end of the $21^{\text {st }}$ day, all the extract-treated groups recorded normal fasting blood glucose level and remained stable till the end of the experimental period of 21 days. This indicates the efficacy and potency of M. aboensis in lowering the blood glucose level of alloxaninduced diabetic rats. When the group treated with Metformin i.e. the reference drug (Group 2) was compared to groups treated with the extract, there was no significant difference ( $p>0.05)$ except in Groups 7 and 8 which recorded a significantly higher glucose levels $(p<0.05)$ at the end of day 14. At the end of 21 days of treatment with the extract, it was observed that there was no significant difference $(\mathrm{p}>0.05)$ in the fasting blood glucose level when Groups $4-8$ were compared to Groups 1 and 2. However, there was no reduction in the blood glucose level of the Group 3 (negative control) diabetic rats when compared to Groups 1, 2, 4 - 8 .

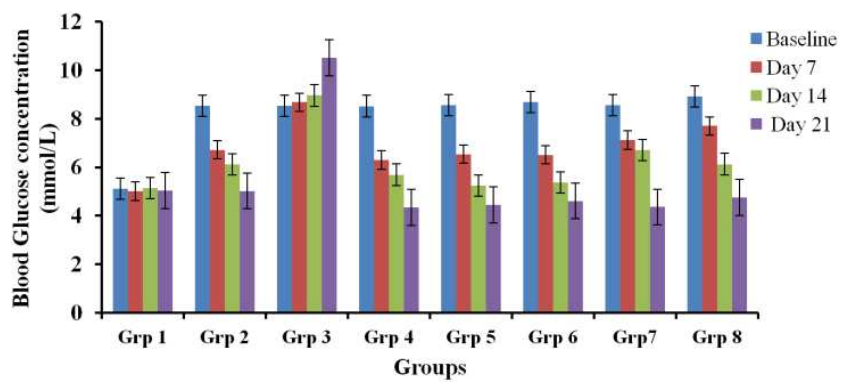

Figure 1. Effect of aqueous leave extract of M. aboensis on blood glucose concentration of alloxan-induced diabetic rats.

Results in Fig. 2 showed no significant difference $(\mathrm{p}>0.05)$ in mean total cholesterol levels of groups 2 - 8, when compared to Group 1 (normal control). A significant decrease $(\mathrm{p}<0.05)$ in mean triacyglycerol and LDL levels was observed in Groups $4-8$ treated with leaf extract of $\mathrm{M}$. aboensis as well as in Group 2 treated with the reference drug when compared to the normal control group (Group 1). Similarly, Groups $5-8$ that received higher doses of the extract had significantly reduced $(p<0.05)$ TAG when 
compared with the normal, positive and negative controls. There was a significant increase $(\mathrm{p}<0.05)$ in mean HDL levels of extract-treated groups as well as in Group 2 treated with the reference drug when compared to Group 1. However, there was neither reduction in the blood CHOL, LDL, and TAG levels nor an increase in HDL level of Group 3 (negative control) diabetic rats when compared with the normal, positive and extract-treated groups.

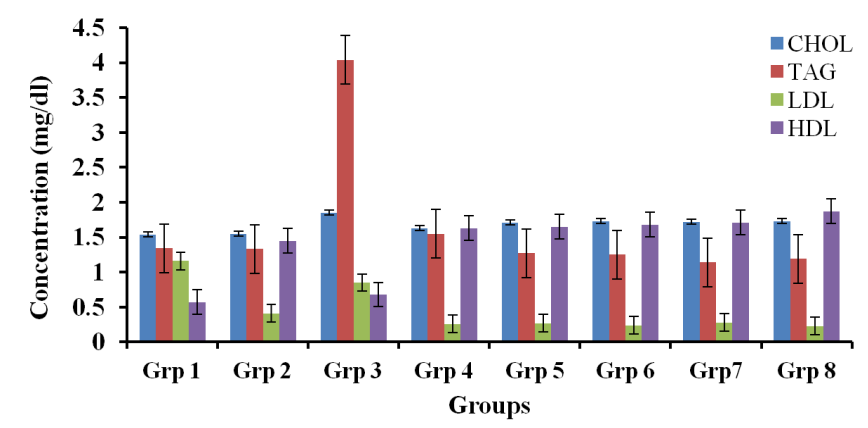

Figure 2. Effect of aqueous leave extract of M. aboensis on lipid profile of alloxan-induced diabetic rats.
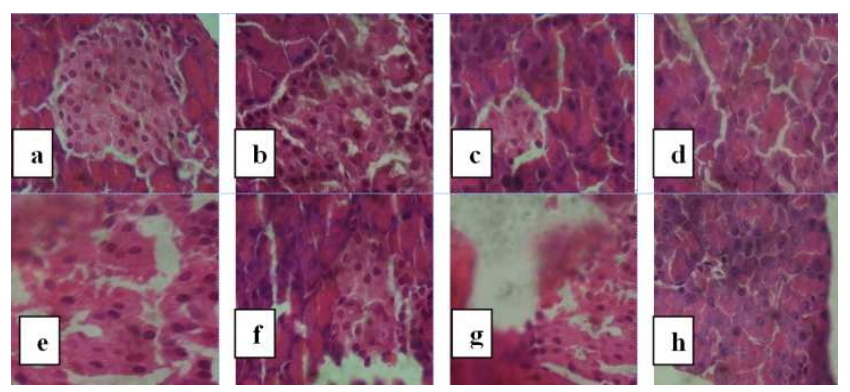

Plate 1. Histopathological changes in pancreas of control and experimental rats after 5 days of administration of alloxan. a. Group 1 - Normal pancreas, $b-f$. Groups 2-6 show atrophic pancreatic islet; g. Group $7-$ shows bulky atrophic pancreatic islet with vacuolations; $h$. Group $8-$ shows atrophic pancreatic islet.
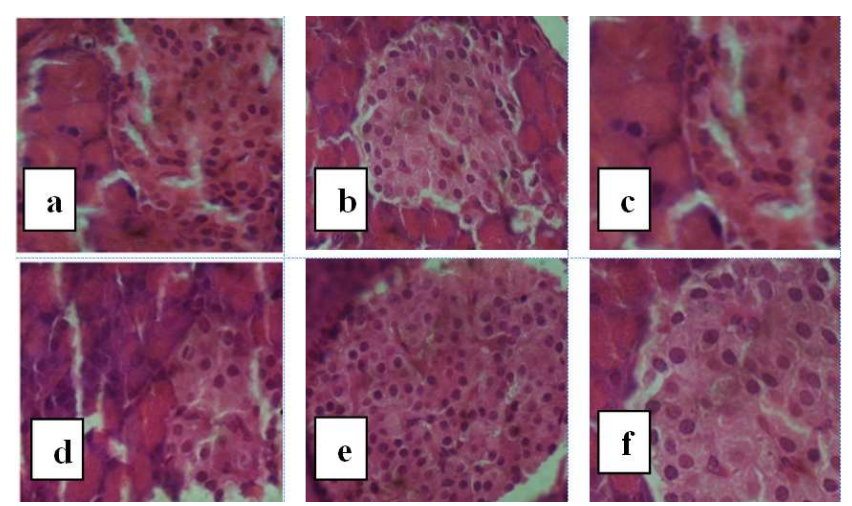

Plate 2. Histopathological changes in pancreas of experimental rats 14 days after treatment of alloxan- induced diabetes with reference drug and aqueous leaf extract of M. aboensis. a. Group 2 - Normal pancreatic islet; $b$. Group 4 - Normal pancreatic islet; c. Group 5 - atrophic pancreatic islet; d. Group 6 -Normal pancreatic islet; e. Group 7 - Bulky pancreatic islet; $f$. Group 8 -Normal pancreatic islet

Photomicrographs (Plate 1) of the pancreas of experimental rats taken 5 days after administration of alloxan showed the presence of bulky, vacuolated and atrophic pancreatic islets in all the groups except for the normal control group (Group 1). However, 14 days after treatment with reference drug and aqueous leaf extract of M. aboensis, photomicrographs (Plate 2) showed normal pancreatic islets in Groups 2, $4-8$, while bulky, vacuolated and atrophic pancreatic islets were observed in Group 3.

\section{Discussion and Conclusion}

In the present work, anti-diabetic and anti-lipidemic activities of oral administration of aqueous leaf extract of $\mathrm{M}$. aboensis in, and its effect on pancreatic histology of, alloxaninduced diabetic rats were investigated. Alloxan causes diabetes through its ability to destroy the insulin producing beta cells of the pancreas. Administration of alloxan increased blood sugar and lipid levels when compared to normal rats and also induced persistent diabetes mellitus in rats. The results of the present study indicated that the leaf extract of M. aboensis was capable of reducing blood glucose level associated with diabetes. Diabetic rats treated with the leaf extract showed reduction in blood glucose in comparison to untreated diabetic rats and the results indicate the efficacy of aqueous extract of $\mathrm{M}$. aboensis in decreasing the blood glucose level in alloxan-induced diabetic rats. The glucose lowering activity observed in the diabetic animals may be due to the stimulation of $\beta$ - cells of pancreatic islets [21]. This effect may also be due to the presence of tannin, saponin, flavonoids and other constituents present in the leaf of M. aboensis [16], which could act synergistically or independently in enhancing its anti-diabetic property.

Similarly, a dose-dependent decrease in total cholesterol, triglyceride and LDL levels and an increase in HDL levels was observed in diabetic rats treated with the extract while similar results were observed in the group treated with Metformin. This result agrees with the observation of [10] that lipid abnormalities are commonly associated with diabetes, particularly in those with type 2 diabetes. They stated that most common lipid abnormalities in these patients include hyper-triglyceridemia and reduced high-density lipoprotein (HDL) cholesterol levels. While lipid abnormalities typically improve with better glycemic control, normalization does not usually occur. Similarly, [9] and [11] opined that because there is a strong relationship between all forms of vascular disease in patients with type 2 diabetes and hyperlipidemia, it is important to screen for and treat these lipid abnormalities. Blood glucose levels of the non-treated diabetic rats were consistently higher than the hypoglycemic drug-treated and $\mathrm{M}$. aboensis leaf extract-treated groups. This suggests that optimum glycemic control can be achieved by the use of dosage-regulated control of leaf extract of M. aboensis. Furthermore, the treatment of alloxan-induced hyperglycemic rats with Metformin and leaf extract of $\mathrm{M}$. aboensis protected the animals from the prefrontal lesions observed in the nontreated diabetic rats. These results were in agreement with other previous studies on anti-diabetic and antioxidant effect of Scoparia dulcis in alloxan-induced albino mice [22, 23] and anti-diabetic effect of T. arjuna bark leaf extract [24]. 
Photomicrograph of alloxan-induced diabetic pancreas showed atrophic pancreatic islet with vacuolations which indicates significant damaged Islets of langerhans in the beta cells. [24] and [25] have earlier reported that the ultrastructure of alloxan diabetic pancreas showed considerable reduction in the islet of langerhans as well as depleted islets. The alloxan-induced diabetic rats showed pancreatic islet regeneration after treatment with extracts of $\mathrm{M}$. aboensis. The regenerative effect of extract on the pancreatic cells may enlighten the positive effects of $M$. aboensis on the production of insulin.

Continued glucose level monitoring indicated that leaf extract of $M$. aboensis has anti-diabetic and anti-lipidemic properties and can be used to treat diabetes induced by alloxan since it was capable of controlling the glucose level in the blood in a way similar to the reference drug which works by decreasing the amount of glucose produced by the liver and increases the uptake of glucose by the cells of the body. Furthermore, photomicrographs of pancreatic cells showed that the extract may be effective in its capacity to restore pancreatic cells that were hitherto damaged by alloxan.

Further studies will be on evaluation of the toxicity profile and elucidation of the structures of active phytochemical components present in the leaf extract of M. aboensis.

\section{References}

[1] Shaw, J.E., Sicree, R.A., and Zimmet, P.Z. (2010). Global estimates of the prevalence of diabetes for 2010 and 2030. Diabetes Research and Clinical Practice, 87: pp 4-14.

[2] Kumanyika, S.K., Obarzanek, E., Stettler, N., Bell, R., Field, A.E., Fortmann, S.P., Franklin, B.A., Gillman, M.W., Lewis, C.E., Poston, W.C., Stevens, J. and Hong, Y. (2008). Population-based prevention of obesity: the need for comprehensive promotion of healthful eating, physical activity, and energy balance: a scientific statement from American Heart Association Council on Epidemiology and Prevention, Interdisciplinary Committee for Prevention (formerly the Expert Panel on Population and Prevention Science). Circulation, 118(4): pp 428-464.

[3] World Health Organization. (1999). Definition, Diagnosis and Classification of Diabetes Mellitus and its Complications: Report of a WHO Consultation. Part 1: Diagnosis and Classification of Diabetes Mellitus. Geneva, World Health Org.

[4] Petal, M. and Rybczynski, P. (2003). Treatment of non-insulin dependent diabetes mellitus. Expert Opinion on Investigational Drugs, 12(4): pp 623-633.

[5] Winifred, O. (2008). Leadership of all Rights. Distributed by all Africa Global Media Retrieved from: http://www.allafrica.com.

[6] Agabegi, S. and Agabegi, E. (2008). Step-up to Medicine (StepUp series). Hagerstown, MD: Lippincott, Williams \& Wilkins.

[7] Bennett, K., James, C., Mutair, A., Al-Shaikh, H., Sinani, A. and Hussain, K. (2011) Four novel cases of permanent neonatal diabetes mellitus caused by homozygous mutations in the glucokinase gene. Pediatric Diabetes 12 (3 Pt 1): pp 192-196.
[8] Gyang, S. S., Nyam, D. D. and Sokomba, E. N. (2004). Hypoglycemic activity of Vernonia amygdalina (chloroform extract) in normoglycemic and alloxan-induced hyperglycemic rats. Journal of Pharmacy and Bioresources, 1(1): pp 61-66.

[9] Haffner, S. M., Mykkanen, L., Festa, A., Burke, J. P. and Stern, M. P. (2000). Insulin-resistant prediabetic subjects have more atherogenic risk factors than insulin-sensitive prediabetic subjects: implications for preventing coronary heart disease during the prediabetic state. Circulation, 101(9): pp 975-980.

[10] Coresh, J., Kwiterovich, P. O. Jr., Smith, H. H. and Bachorik, P. S. (2006). Association of plasma triglyceride concentration and LDL particle diameter, density, and chemical composition with premature coronary artery disease in men and women. Journal of Lipid Research, 34(5): pp 1687-1697.

[11] Austin, M. A., King, M. C., Vranizan, K. M. and Krauss, R. M. (2009). Atherogenic lipoprotein phenotype: a proposed genetic marker for coronary heart disease risk. Circulation, 82: pp 495-506.

[12] Aguwa, C. N., Ukwe, C. V., Inya-Agha, S. I. and Okonta, J. M (2001). Anti-diabetic effect of Picralimanitida aqueous seed extract in experimental rabbit model. Journal of Natural Remedies, 1(2): pp 135-139.

[13] Szkudelski, T. (2001). The mechanism of alloxan and streptozocin action in $\beta$-cells of the rat pancreas. Physiological Research, 50(6): pp 537-546.

[14] Lenzen, S. (2008). The mechanisms of alloxan- and streptozotocin - induced diabetes. Diabetologia; 51(2): pp 216-26.

[15] Lachin, T. and Reza, H. (2012). Anti diabetic effect of cherries in alloxan-induced diabetic rats. Recent patents on endocrine, metabolic and immune drug discovery, 6(1): pp 67-72.

[16] Onyegeme-Okerenta, B. M. Onyeike, E. N. and Esialekpe, F. O. (2013) Effect of ethanol leave extract of millettia aboensis on selected haematological indices of Wistar albino rats. Global Advanced Research Journal of Medicinal Plants, 2(1): pp 004-011.

[17] Onyegeme-Okerenta, B. M. and Okafor, U. A. (2014). Antimicrobial properties of ethanol leaf extract of Millettia aboensis on some selected clinical Isolates. Universal Journal of Plant Science; Vol. 2 (5): pp. 97-101.

[18] Burkill, H. M. (2005). The useful plants of West Tropical Africa. Vol. 3, $1^{\text {st }}$ Edition, Royal Botanical Garden, Kew, ISBN:10-0947643648.

[19] Viana, G.S., Medeiros, A.C., Lacerda, A.M., Leal, L.K., Vale, T.G. and Matos, F.J. (2004). Hypoglycemic and anti-lipemic effects of the aqueous extract from Cissus sicyoides. BioMedCentral Pharmacology, 8: pp 4-9.

[20] Brown, H. S. (2002). Hematoxylin and eosin (the routine stain). $\mathrm{H}$ \& $\mathrm{H}$ informational primer. Sigma-Aldrich Corporation, pp 1-3.

[21] Krishnakumar, K., Augusti, K. T. and Vijayammal, P. L. (1999). Hypoglycemic and anti-oxidant activity of Salacia oblonga wall extract in streptozotozin induced diabetic rats, Indian Journal of Physiology and Pharmacology, 43(3): pp $510-514$. 
[22] Zulfiker, A. H., Ripa, F. A., Rahman, M., Ullah, M. O., Hamid, K., Khan, M.R. and Rana, S. (2010). Anti-diabetic and Antioxidant Effect of Scoparia dulcis in Alloxan induced Albino Mice. International Journal of Pharmtech Research, 2(4): pp 2527-2534.

[23] Aparna, T., Manabendra, D. C. and Biplab, D. E. (2013). Hypoglycemic activity of Scoparia dulcis L. in different solvent systems. International Journal of Pharmacy and Pharmaceutical Sciences, 5(3): pp 330-332.
[24] Ragavan, B. and Krishnakumari, S. (2006). Anti-diabetic effect of T. Arjuna bark extract in alloxan-induced Diabetic rats. African Journal of Biomedical Research, 9 (3): pp 189 197.

[25] Gholamali, A.T., Maleki, M., Matudayen, M. H. and Sines, S. (2005). Effect of fenugreek, onion and garlic on blood glucose and histopathology of pancreas of alloxan-induced diabetes rat. Indian Journal of Medical Sciences, 59(2): pp 64 -69 . 